\title{
SMOKING AND OCULAR DISEASE-AN UPDATE
}

\author{
Sood A*, Badhu B, Dulal S*, Kumar $S^{*}$
}

Smoking is an important but under estimated cause of ocular morbidity. The signs 'No Smoking and "Cigarette Smoking is injurious to health" are such a common sight that its grave implication is indifferently ignored. How many ophthalmologists remember to give this warning to their patients affected by diseases like age related macular degeneration and cataract is a matter of concern.

Tobacco is the leading cause of systemic and ocular disease, disability and premature death. ${ }^{1}$ Nepal is one of the top consumers of tobacco in various forms. Annual production accounts for $0.12 \%$ of the world total. The consumption of Bidi is more prevalent than the consumption of manufactured cigarette in Nepal. Along with cigarettes\& Bidis, tobacco is used in form of hookah, Soti, sulpha \& other locally made tobacco products. The nicotine level in cigarettes in Nepal is $1.5-2.5 \mathrm{mg}$.

Smoking is seen to be a concurrent habit along with alcoholism in a large percentage of people, thereby compounding the mortality and morbidity due to mixed aetiological factors.

\section{PREVALENCE}

In a survey in 1983, prevalence of smokers was found to be $73.7 \%$ ( $85.4 \%$ males and $62.4 \%$ females) Prevalence rates differed from $77 \%$ in the high mountains to $37 \%$ in urban Kathmandu. In 1990 9.4\% of all male smokers and 1.6\% of female smokers were found to be smoking $>20$ cigarettes per day (The 1993 Report on Global Status of Tobacco Consumption: World Health Organization). The prevalence was higher in the less educated and socio-economically backward strata of society. The average adult per capita consumption of cigarettes averaged 580 in the early 1990's as compared to 170 in the early 1970's (Table I).
Table I : Annual Cigaratte Consumption in Nepal

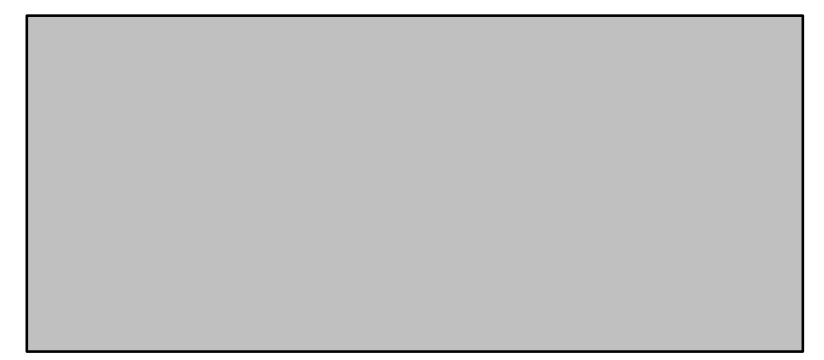

Source : International Tobacco Guide

\section{CONSTITUENTS OF TOBACCO SMOKE}

There are about 4000 active chemicals in tobacco smoke, more than 40 of these chemicals are carcinogens, and many others are deleterious to the cardiovascular and the pulmonary systems. ${ }^{1}$ They include nicotine, tars, nitrosamines, polycyclic aromatic hydrocarbons, hydrogen cyanide, formaldehyde and carbon monoxide. These toxic compounds have multiple adverse physiological effects and many of them produce profound pathologic disturbances in different organs, including the eye.

\section{SOME MAJOR OCULAR DISEASES DUE TO SMOKING}

1. Chronic Irritable eye

2. Cataract

3. Age related macular degeneration

4. Retinal Vascular disorders

5. Tobacco amblyopia

6. Ischemic optic Neuropathy

7. Thyroid eye disease

8. Malignancy

9. Open angle Glaucoma

10. Diabetic Retinopathy

11. Ocular Sarcoidosis

12. Miscellaneous - Nystagmus, Strabismus, Retinal Detachment, Leber's Optic Neuropathy.

* B.P. Koirala Institute of Health Sciences, Dharan, Nepal.

Address for correspondence : Dr. Archana Sood 
The conjunctival mucosa is highly sensitive to airborne chemicals, fumes and irritative gases that originate in tobacco smoke in active and passive smoking. ${ }^{2}$ Excessive lacrimation, stinging, burning, pricking sensations are common symptoms and conjunctival congestion with metaplastic changes in mucosa may be seen. A study on the influence of exposure to environmental tobacco smoke (ETS) in an aircraft, on measured and perceived cabin air quality, nasal patency and biomarkers in nasal lavage fluid was conducted by Weislander et $\mathrm{al}^{3}$ in 2000. He concluded that despite a high air exchange rate and spatial separation between smokers and non-smokers, smoking in commercial aircraft may cause significant air pollution, as indicated by large increase in the number of respirable particles. This ETS exposure is associated with an increase in ocular and general symptoms, decreased tear film stability and alterations of nasal patency.

An acceptable level of cigarette smoke that an average healthy person can be exposed to is one that produces a carbon monoxide concentration of $1.5-2.0$ ppm. ${ }^{1}$ To avoid exceeding the upper limit of $2.0 \mathrm{ppm}$, it is necessary to have a fresh air supply of $33 \mathrm{~m}^{3} / \mathrm{h} /$ cigarrette smoked. Not all public places have facilities for such a high volume of ventilation.

\section{CATARACT}

Cataract is the main cause of preventable blindness and visual impairment all over the world and in Nepal it is responsible for $65 \%$ amongst all blindness.

Nuclear sclerosis appears to be the type of cataract most commonly associated with smoking.

Smoking induces cataract formation by imposing an oxidative challenge (in addition to age and Ultra-violet related antioxidant depletion), thus contributing to the depletion of the endogenous antioxidant pool. It is well known that oxidative damage plays a major role in cataractogenesis. ${ }^{4}$

Tobacco smoke also contains large amounts of heavy metals like cadmium, lead and copper which accumulate in the lens and exert further toxicity. The association of long-term smoking was studied by McCarty CA et $\mathrm{al}^{5}$ in 2000 as a part of quantifying attributable risk factors for cortical, nuclear and posterior sub capsular cataracts. Smoking for $>30$ years was found to be a significant risk factor for development of cataract, especially nuclear cataract. Brian G et al in 2001 stated that decreased smoking might benefit in delaying cataract along with decreased UV - B and radiation exposure. ${ }^{6}$
This disease is one of the leading causes of irreversible visual loss in patients $>65$ years age. The pathogenesis of ARMD is a complex interaction of genetic and external factors ${ }^{7}$. Genetic factors may be involved and familial disposition is seen in $50 \%$ of the cases. ${ }^{8}$ Risk factors include gender, arterial hypertension, arteriolosclerosis, elevated serum lipids, smoking, alcohol and ultraviolet light. ${ }^{8}$ Many studies have proved that smoking is an important risk factor for this age related disorder and tobacco smoking is the principal known preventable exposure associated with any form of ARMD.?

Smoking is known to affect choroidal blood flow in the eye, as well as promote ischemia, hypoxia and micro infarctions, all of which could increase the susceptibility of the macula to degenerative changes. Smoking also increases the oxidative stress and lipid per oxidation and reduces the plasma concentrations of antioxidants. ${ }^{10}$ The role of antioxidants in the pathogenesis of ARMD is already well understood. Since limited treatment modalities are available for this disease, ${ }^{8}$ advice of avoiding or quitting smoking is an important preventive measure to be kept foremost in mind.

\section{RETINAL VASCULAR DISORDERS}

Smoking is considered a major risk factor in most ischemic disorders, affecting the ocular vasculature at various levels. Both erythrocyte and leucocyte levels are elevated in smokers, and platelets are activated in the blood of long-term smokers. These factors contribute to hyperviscosity and an increased risk of thrombosis. Nicotine, a principal ingredient of tobacco smoke, causes stimulation of adrenergic vascular receptors, leading to vasoconstriction. The increased carbon monoxide concentration in blood that results from cigarette smoking decreases the oxygen carrying capacity of haemoglobin. These factors further contribute to smoking induced ischemic and hypoxic environment of the tissues. ${ }^{11}$ Amaurosis fugax, a transient episode of monocular visual loss, is commonly seen in smokers. Tobacco smoke accelerates the rate of atherosclerosis and retinal emboli, composed of cholesterol or platelet fibrin aggregate are responsible for these transient ischemic spells or even retinal infarction. ${ }^{12}$ Smoking is also a risk factor for retinal artery occlusion. ${ }^{13}$

According to a study by Klein $\mathrm{R}$ et al in 2000, Retinal vein occlusion was strongly associated with smokers as compared to non smokers (odds ratio 4.43,95\% confidence interval 1.53, 12.84), apart from other risk factors. ${ }^{14}$ 
TOBACCO AMBLYOPIA

This is an important cause of bilateral optic neuropathy and is characterized by a distinct bilateral severe visual disturbance, symmetrical scotomas and colour vision defects. According to Mojon D et al, ${ }^{15}$ smoking interrupts mitochondria function and ocular tissues with high energy consumption and dependence on oxidative energy production, like optic nerve and retina are often involved in mitochondria diseases like optic neuropathy, retinal degeneration, decreased ocular motility and unilateral ptosis. Optic nerve has been found to be more vulnerable to tobacco smoke than peripheral nerves. ${ }^{16}$

Cyanide detoxification incapacity and deficiency of Vitamin B12 are possible causes of tobacco amblyopia. Jestico JV et $\mathrm{all}^{17}$ have reported raised whole blood cyanide levels in patients with tobacco amblyopia (approaching lethal levels reported from acute cyanide inhalation). This is due to the impaired cyanide detoxification in cigarette smokers.

An interesting new neuro-ophthalmological sign was reported by Kellen $\mathrm{R}$ et al -He described a yellow forelock in a in a middle aged man with loss of vision in both eyes Rizzo JF et $\mathrm{al}^{19}$ reported 2 cases of tobacco amblyopia out of which one recovered with cessation of smoking, indicating the beneficial role of avoiding tobacco in this condition.

\section{ISCHEMIC OPTIC NEUROPATHY}

Decreased blood flow at the papilla has been demonstrated by Lietz-Partzch $\mathrm{A}$ et $\mathrm{al},{ }^{20}$ as recorded by the Heidelberg retina flowmeter, shortly after smoking a cigarette. The association of smoking with Ocular ischemic syndrome was seen in a case reported to have sub acute painful visual loss in which there was a common carotid artery occlusion but no cerebral involvement. ${ }^{21}$ Anterior Ischemic optic neuropathy is a disease characterized by acute painless loss of vision. Vascular infarction of the posterior ciliary circulation is believed to be the cause, and its association with systemic vascular disorders which compromise blood flow to the optic nerve head is well established. Tobacco smoke further causes damage to the optic nerve and its blood supply. Oku $\mathrm{H}$ et al, ${ }^{21}$ experimentally demonstrated demyelination of the retrobulbar portion of optic nerve by exposing rats to tobacco smoke.

Chung et al, ${ }^{22}$ by analyzing the smoking habits of 137 patients suffering from non-arteritic AION, identified cigarette smoking as an important risk factor in its development.

\section{THYROID EYE DISEASE}

Cessation of smoking is an important local measure in the treatment of thyroid eye disease according to Comblatt et al, ${ }^{23}$ apart from achievement of a euthyroid state, artificial tears and assessment for development of optic neuropathy, proptosis, diplopia and lid abnormalities.

Tobacco ingredients competitively inhibit iodine uptake and organification in the gland. The influence of smoking on the sympathetic nervous system also affects thyroid function. ${ }^{24}$

The hypoxia induced by vasoconstriction due to nicotine, stimulates protein synthesis and extra-ocular muscle derived fibroblast proliferation leading to hypertrophy \& Graves ophthalmopathy.

\section{MALIGNANCY}

Ocular metastasis in carcinomas related to smoking (e.g. lung carcinoma) have been reported by Hasturk et al..$^{25}$ A patient with basaloid large cell lung carcinoma presented concurrently with a metastatic uveal tumour, leading to retinal detachment. Small cell carcinoma of the lung may present with ptosis and Homers syndrome if apex of the lung is involved.

\section{OCULAR SARCOIDOSIS}

Tobacco dust is known to contain non biodegradable foreign bodies. Incomplete phagocytosis of these particles evokes an antigenic response in the immunologically susceptible host .Therefore smoke may be an important environmental risk factor for ocular sarcoidosis as was investigated by Merritt JC et al. ${ }^{28}$

\section{OTHERS}

Unaccustomed smoking may elicit transient nystagmus, dizziness, unsteadiness, and nausea. Infrared video nystagmography and posturography were performed simultaneously to study the differential effects of nicotine on the association of ocular motor and postural disturbances in 25 non- or occasional smokers. Sixteen showed nicotineinduced nystagmus (NIN) of various directions (mainly horizontal or upbeat), which was associated with a significant increase in postural sway after smoking. Transient ocular motor and postural effects are compatible with simultaneous nicotine-induced effects on the vestibulo-ocular and vestibulospinal functions. ${ }^{29}$

\section{TOBACCO CONTROL MEASURES IN NEPAL}

\section{Control on Tobacco Products}

The Government is preparing a national plan for tobacco control. In May 1992, the Ministry of Health created a National 
Anti-Tobacco Committee, which also included representation from several non-governmental organizations. Currently, it is compulsory for tobacco products to carry a health warning. A portion of the tobacco tax is used for public health improvement.

\section{Protection for non-smokers}

Smoking is banned in health care institutions, except in designated smoking areas. Since 1992, the government has prohibited smoking in public places, public transport, cinema halls, and other locations. Smoking is also banned on domestic flights and flights from neighbouring countries.

\section{Health education}

Nepal's Ministry of Health and local NGOs, including medical organizations, are involved in health education about the hazards of smoking, through lectures, radio, newspapers, magazines, posters and pamphlets. Although a large proportion of adults are now aware of the hazards of smoking, a number of smokers are still not concerned about the effects on their own health, or on the health of others.

\section{CONCLUSION}

The role of smoking in ocular morbidity cannot be stressed enough. Tobacco amblyopia, optic neuropathies and ischemic vascular disorders are of major concern due to their sight threatening implications. Cataract, ARMD, thyroid disease, sarcoidosis, nystagmus, strabismus and chronic irritable eve amplify the ocular morbidity. Both ocular and systemic malignancies can be life threatening.

Passive smoking is another hazard and risk for the innocent non -smokers, therefore the importance of imposing a policy of non-smoking in public areas and "Quit Smoking" campaigns cannot be underestimated. Given the magnitude and seriousness of cataract problem, an important preventive measure in fighting this disorder is to quit smoking. Enforcement of control measures on the part of government, health education on smoking hazards by doctors and personal resolve by the patient to quit smoking could collectively and effectively contribute to decrease in the incidence of smoking related ocular and general diseases.

\section{METHOD OF LITERATURE SEARCH}

Literature selection for this review was based on a MEDLINE search of the past 18 years for all articles using the keywords 'smoking', 'ocular', 'cigarette' and ophthalmology'. The source of tobacco related mortality, production, consumption and control, measures in Nepal was The 1993 Report on Global

Status of Tobacco Consumption (World Health Organization).

\section{REFERENCES}

1. Solberg Y, Rosner M, Belkin M. The association between cigarette smoking and ocular disease. Survey of Ophthal. 1998:42(6): 535-544.

2. Gometto-Muniz J E, Cain WS. Sensory irritation, relation to indoor air pollution. Ann N.Y. Acad Sci. 1992; 641:137-151.

3. Weislander G, Lindgren T, Norback D, Venge P: Changes in nasal and ocular signs and symptoms of aircrews in relation to ban on smoking in intercontinental flights. Scand J Work Environ Health. 2000; 26(6): 514-22.

4. HeskerH.Antioxidative vitamins and cataracts in theelderly.Z Erahrung Swiss 1995;34:167-176.

5. Mc CartyCA,Nanjan MBJ aylorHR.Attributable riskestimates forcataractto prioritize medical and public health action.Invest Ophthalmol Vis Sci.2000;41(12):3720-5.

6. Brian $\mathrm{G}$, Taylor $\mathrm{H}$ (cataractBlindness-challenges for the $21^{\text {st }}$ century)Bull World Health Organ. 2001; 79(3): 249-56.

7. Hyman L,Neborsky R.Risk factors for ARMD, an update.Curr Opin Ophthalmol. 2002; 13(3): 171-5

8. Korner Stiefbold U. Age Related macular degenerationTherapeutic possibilities and newapproaches. TherUmsch. 2001:58(1): 28-35.

9. SmithW,AssinkJ ,KlienR etal. Riskfactors forARMD-Pooled findings from three continents. Ophthalmology. 2001 ;697704.

10. Suyker WS,Kaplan LA,Stien EA etal. The relation of diet, cigarette smoking and alcohol consumption to plasma beta carotene and alpha-tocopherol levels. AmJ Epidemiol. 1988; 127; 283-296.

11. Benowitz NL. Clinical phamacology of nicotine. Ann Rev Med.1986;37;27-32

12. TippinJ .Corbett J J KerberRE etal. Amaurosis fugaxand ocular infarction in adolescents and young adults. Ann Neurol. 1989:26:69-77.

13. WongDF, llsenPF, BrightDcetal. Case presentations of Retinal arteryocclusion.Optometry.2000:71(11):703-14.

14. Klien R,Klien BE,Moss SE etal.The epidemiology of Retinal vein occlusion. :The Beaver dam eye study.Trans Am Ophthalmol Soc.2000-.98:133-41.

15. Mojon D.Eya diseases in mitochondrial encephalomyopathies.ther Umsch; 2001:58(1); 49-55.

16. Oku H.Fukushima K,Sako H etal.Chronic toxicity of tobacco smoke on visual system. Nippon Ganka Gabbai Zasshi. 1989: 93 (5): 617-24. 
17. J estico J V,O'Brien MD.J eoh R etal.Whole blood cyanide levels in patients with tobacco amblyopia.J Neurol Neurosurg Psychiatry. 1984:47(6):573-8.

18. Kellen RI, Schrank B, Burde RM. Yellow forelock-a neuroophthalmological sign. BrJ Ophthalmol. 1990: 74 (8): 509-10.

19. RizzoJ F,LesselS.Tobbacoamblyopia.AmJ Ophthalmol. 1993. 15: $116(1)$ : 84-7.

20. Lietz-PartzschA, Griesser SM.FlammerJ etal.Decreased Heidelberg Retina flowmeter(HRF) parameter flow at the papilla shortly after smoking a cigarette. Klin Monastbl Augenheilkd. 2001; 218 (5): 332-4.

21. Karacostas DJ ersidon C, Voutas $\mathrm{S}$ et al. Isolated ocular ischemic syndrome with no cerebral involvementin common carotid occlusion. EurJ Ophthalmol. 2001,11 (1): 97.101.

22. Chung SM, GayCA, McCraryJ A. NonArtitic ischemic optic neirppathy. The impact of tobacco use. Ophthalmology: 1994:101.781-83.

23. ConmblattWT. Thyroid eye disease: Current treatoptions Neurol. 2000; 2 (5); 401-6.
24. Bertelsen J B, Hegedus L. Cigarette smoking and the thyroid 4; 1994:327-331.

25. Hasturk S, Soylu M, Zoron E etal. Basaloid large cell lung carcinoma presenting concurrently with metastatic uvoal fumor. Lung Cancor; 2001:32 (1): 95-101.

26. QuigleyHA, WestSK, Rodrogiez J etal. The prevalence of glaucoma in a population-based study ofHispanic subjects; Proyecto VER. Arch Ophthalmol 2001: 119(12): 1819-26.

27. Mouton DP, Gill AJ . Prevalence of diabetic retinopathy and evaluation of risk factors.

28. Merit J C, Ballard DJ , Checkoway H etal. Ocular sarcoidosis. A case control study among black patients. Ann N. Y. Acad Sci 1986; 465; 619-624

29. Periera CB, StruppM, HolzloitnorT et Smoking and balance; A correlation of nicotine induced Nystagmus and postural body sway. Neuroreport2001- 12 (6)-1223-6.

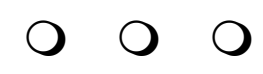

